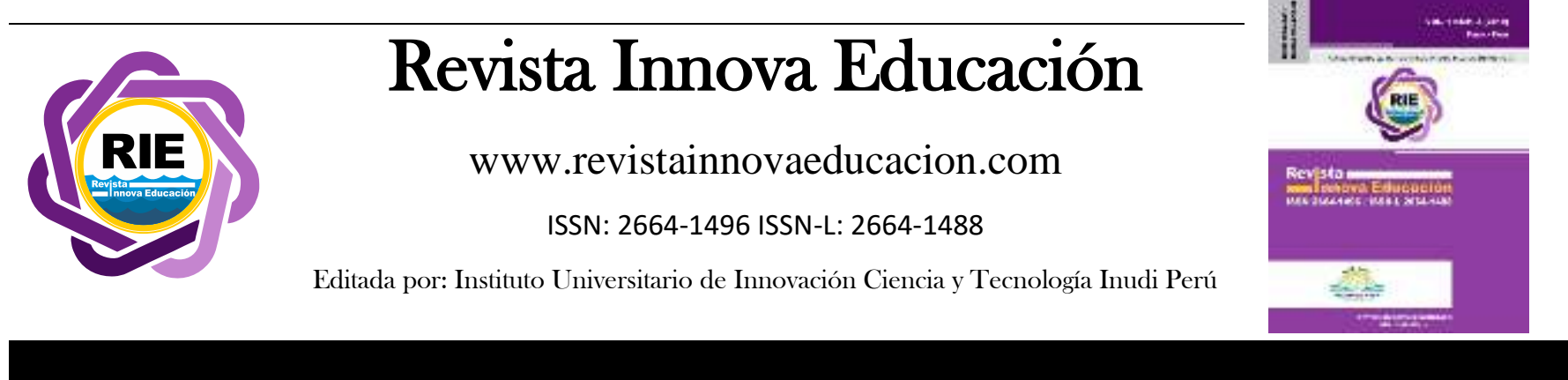

\title{
Gestión de prácticas eco amigables con el medio ambiente en supermercados: una percepción de estudiantes universitarios y gerentes
}

\author{
Management of ecofriendly practices with the environment in supermarkets: a perception of \\ university students and managers
}

\author{
Tomás Véliz ${ }^{1}$ \\ Universidad Nacional del Altiplano de Puno, Puno-Puno, Perú \\ Dttps://orcid.org/0000-0003-4383-0365 \\ Carol Véliz-Gonzales \\ Universidad Católica San Pablo, Arequipa-Arequipa, Perú \\ (D) https://orcid.org/0000-0002-9078-0762 \\ Mario Silva \\ Universidad Nacional del Altiplano de Puno, Puno-Puno, Perú \\ https://orcid.org/0000-0001-5709-7403 \\ Rafael Escobedo \\ Universidad Nacional del Altiplano de Puno, Puno-Puno, Perú \\ https://orcid.org/0000-0001-6011-8033
}

DOI: https://doi.org/10.35622/j.rie.2020.03.007

Recibido 29/03/2020/ Aceptado 25/07/2020 Publicado 25/07/2020

\begin{tabular}{l|l}
\hline ARTícULO ORIGINAL & $\begin{array}{l}\text { Las empresas tienen como eje lo eco sostenible y su contribución de } \\
\text { PALABRAS }\end{array}$ \\
Sustentabilidad, está encaminada a repensar nuevas prácticas de \\
comercialización de productos ecológicos y disposición de residuos, \\
comprometidos con el medio ambiente. Objetivo: Describir e interpretar la
\end{tabular}

${ }^{1}$ Correspondencia: tveliz@unap.edu.pe 
ingresos y reducción de gastos. Conclusión: La construcción de las bases empíricas del modelo de gestión eco amigable son: Productos, envases y eco etiquetas. Residuos, energía y agua. Comunicación e infraestructura ambiental.

\begin{tabular}{ll}
\multicolumn{1}{c}{ KEYWORDS } & $\begin{array}{l}\text { Companies focus on eco sustainability and their contribution to sustainability } \\
\text { is aimed at rethinking new practices for ecological products and waste disposal, } \\
\text { ecofriendly, } \\
\text { ecological products, } \\
\text { solid waste, } \\
\text { supermarkets }\end{array}$ \\
committed to the environment. Objective: To describe and interpret the \\
management of ecofriendly practices in supermarkets, based on the perception \\
of university students and managers, to contribute towards a model of \\
responsible culture management with the environment in organizations. \\
Method: Qualitative-quantitative, mixed approach, non-experimental design, \\
descriptive and interpretive type. It shows 93 university students and 02 \\
managers, a cross-sectional survey and in-depth interviews. Results: The \\
management of ecofriendly practices in supermarkets is comprehensively rated \\
as regular with 37\% according to the perception of university students; the \\
management of waste energy and water qualifies regular with 30\%, requires \\
attention as centers of new income and reduction of expenses. Conclusion: The \\
construction of the empirical bases of the ecofriendly management model are: \\
Products, packaging and eco-labels. Waste, energy and water. Environmental \\
communication and infrastructure.
\end{tabular}

\section{INTRODUCCIÓN}

El escenario de globalización ha intensificado la competencia en el sector supermercados y su orientación medio ambiental. Los supermercados (con área entre $400 \mathrm{~m} 2$ ) y los hipermercados (con área entre $25000 \mathrm{~m} 2$ ) venden gran surtido, con media de 40 cajas de salida y el área supera $\operatorname{los} 2500 \mathrm{~m} 2$ (Chullo, 2017).

Vivimos el auge de las empresas verdes, bajo la comercialización de productos ecológicos, socialmente responsables, conciencia y compromiso de causar el menor impacto posible al medio ambiente (Molina, 2011). Los negocios sostenibles presentan actividades amigables, no tienen impacto negativo con el medio ambiente y obtienen beneficios económicos (producción más limpia, energías renovables, edificios inteligentes, responsabilidad social etc.) (Austermuhle, 2002).

La percepción ambiental de los supermercados desde el segmento estudiantes universitarios (entre 18 a 25 años), son atractivos por ser formatos grandes, modernos, variedad de productos y marcas; sin embargo, se advierten alimentos con información de octógono que superan parámetros técnicos: altos en sodio, en azúcar, en grasas saturadas y grasas transgénicas; estos productos procesados van en contra de la alimentación saludable, un impacto negativo sobre la calidad de vida y el medio ambiente, Por otro lado, los supermercados generan grandes 
cantidades de residuos sólidos y líquidos, presentando limitaciones en disposición y valoración de sus residuos para la preservación del medio ambiente.

A fin de entender la importancia de las actividades y prácticas eco amigables con el medio ambiente, partimos de la consideración que los supermercados incluyen: Productos ecológicos, productos con eco etiquetas, bolsas biodegradables, lámparas T8 y T5, residuos, energía, agua y capacitación del personal. Ello permite en la gestión eco amigable responsable y sustentable, determinar una taxonomía de tres categorías: productos, envases y eco-etiquetas; residuos sólidos, energía y agua y comunicación medio ambiental (Díaz y Zea, 2017; Storino, 2013).

\section{La gestión de productos ecológicos, envases y eco etiquetas:}

La búsqueda de proveedores con productos biodegradables y compostables, empaques biodegradables (Patarroyo, 2019). Los productos y empaques eco amigables respetan el medio ambiente, y a partir de la forma de descomposición se puede diferenciar en biodegradable (en condiciones naturales), oxodegradable (por proceso de descomposición química) y compostable (termina no solo degradándose sino se convierte en abono). Compostaje es el proceso bioquímico por el cual la materia orgánica (vegetal y animal) por acción de microrganismos se degrada y transforma en compost orgánico (Chanduví, 2006). En la comercialización de productos procesados con el etiquetado en forma de octógono, advierte la norma la alimentación saludable. Esto lo hace notar aún más en las advertencias publicitarias para el rotulado alto en sodio, en azúcar, en grasas saturadas o contiene grasas transgénicas, que superan parámetros técnicos establecidos en normas de promoción de la alimentación saludable (Ley № 30021).

Los envases amigables se consideran ecológicos si es biodegradable (Huella de CO2 baja), reciclable o reutilizable (Bohm y León, 2015). El uso de envases biodegradables y/o reciclables para empacar alimentos contribuye en la construcción de una economía circular (eco diseños y potenciar el reciclaje) (Minam, 2019). En Perú, la Ley Nº 30884 o ley del plástico, se regula el plástico de un solo uso y los recipientes o envases descartables. El uso de recipientes eco-amigables permite al consumidor ser responsable con el medio ambiente, reduce la contaminación ambiental y permite concientizar a la ciudadanía utilizando bolsas de tela o papel para la compra de productos.

\section{La gestión de residuos, energía y agua:}

Los residuos sólidos constituyen sustancias, productos y subproductos en estado sólido o semisólido de los que su generador dispone y está obligado a disponer en virtud a lo establecido 
en la norma nacional o de los riesgos que provocan a la salud y el ambiente, estos deben ser gestionados a través de un sistema que incluya operaciones y procesos (Ley $\mathrm{N}^{\circ}$ 27314). Los residuos inorgánicos como el plástico, aluminio, papel y la mayoría de empaques, es posible aprovecharlos nuevamente por medio del reciclaje (Sedesol, 2001). Los residuos orgánicos en supermercados constituyen los provenientes de manipulación, preparación y consumo en comedores, y de alimentos desechados debido a su degradación.

En los supermercados existen áreas capaces de producir impactos negativos en el medio ambiente, uno de los focos es el área de refrigeración por la cantidad de energía consumida y la generación de desechos sólidos o líquidos (Jara, 2004). El ahorro del agua en las instituciones debe considerar: el control de fugas, avisos sobre el buen uso del agua, comunicar averías de equipos pertinentes, regar jardines en horas de baja intensidad solar (Olivo, 2011).

\section{La disposición y valorización de residuos:}

La disposición de desechos busca la minimización de la cantidad de residuos sólidos y la valorización utiliza las 4R: reducir, reutilizar, reciclar y recuperar los residuos (La Secretaría de Ambiente y Desarrollo Sustentable (2005). En nuestro entender, en gestión de residuos sólidos de supermercados la valorización busca optimizar el uso y disposición de los residuos sólidos y semi sólidos. Las actividades estratégicas en residuos sólidos incluyen: Reducir, es evitar generar basura con la compra de productos solo necesarios. Reutilizar, es dar un segundo uso a la basura antes de desecharla. Reciclar, es usar la materia prima de un producto para producir uno igual o nuevo. Recuperar, es extraer energía o materiales a partir de los residuos.

\section{La comunicación e infraestructura eco amigable:}

En donde la comunicación ecológica informa a los compradores los atributos y beneficios del eco producto que comercializa y la imagen de empresa comprometida e informada en temas medioambientales (Calomarde, 2000). La comunicación ecológica relaciona lo que los consumidores urbanos quieren consumir y encontrar en los productos ecológicos y que las empresas se impliquen con campañas de información sobre productos ambientales, concientización y educación ambiental (Conama, 2016). Se puede notar una doble perspectiva de comunicación, las ventajas de beneficio de los eco productos amigables y por otro lado informar sobre sostenibilidad ambiental y hacer creíble la imagen de empresa sostenible y comprometida con el medio ambiente.

Las empresas en comunicación eco amigable incluyen a consumidores, trabajadores y grupos de interés para comprender el impacto sobre el medio ambiente, involucra cambio de 
actitudes y comportamientos, prácticas y valores de compromiso ambiental. La educación ambiental, es un proceso de mejora continua permanente, busca ofrecer conciencia ambiental, conocimiento ecológico, actitudes y valores, compromiso de acciones y responsabilidades para el uso racional de los recursos y lograr desarrollo sostenible (Esap, 2015). La comunicación y educación amigable tiene como propósito el cambio de actitudes, comportamientos, prácticas y valores de compromiso medio ambiental, algunos temas incluyen sensibilización de compras y ventas verdes, buen uso de los residuos con fines ecológicos, reducir gasto e impacto de deterioro ambiental, concientización de compromiso responsable con el medio ambiente.

La contextualización de prácticas eco amigables ha permito la revisión de antecedentes bibliográficos sobre temas de productos amigables, residuos sólidos, líquidos y comunicación medio ambiental, para impulsar la sostenibilidad como eje de supermercados, responde al siguiente objetivo: Describir e interpretar la gestión de prácticas eco amigables de supermercados, a partir de la percepción de estudiantes universitarios y gerentes, para contribuir hacia un modelo de gestión de cultura responsable con el ambiente en las organizaciones.

\section{MÉTODO Y MATERIALES}

La investigación tiene como ámbito los supermercados de la ciudad de Puno en Perú (Plaza Vea y Negolatina), en el área de responsabilidad social empresarial. La percepción de prácticas eco-amigables se realizó a estudiantes universitarios de la Escuela Profesional de Administración de la Universidad Nacional del Altiplano, y a Gerentes de los principales supermercados de la ciudad.

El enfoque de investigación es de corte mixto cualitativo y cuantitativo, diseño no experimental, tipo de investigación descriptivo e interpretativo. La población está constituida por 664 estudiantes universitarios, la muestra es de 93 estudiantes y 02 ejecutivos de las empresas en estudio. La técnica de encuesta con base en un cuestionario de corte transversal y entrevistas de profundidad.

La implementación del trabajo de campo se inició en coordinación docente y estudiantes del curso ética y responsabilidad social, visita a las instalaciones de las empresas. El estudio se realizó entre agosto del 2019 a enero del 2020.

A los ejecutivos de las empresas se les entrevistó en calidad de expertos en prácticas y estrategias eco-amigables con el medio ambiente, y se complementó con la aplicación de un cuestionario estructurado a los estudiantes para obtener datos consistentes de prácticas ecoamigable ambientales de los supermercados. 
Las respuestas se levantaron como patrón de información para un modelo de gestión de prácticas eco amigables responsables con el medio ambiente de los supermercados.

Para la consolidación del modelo teórico se estableció un patrón de información de gestión de prácticas eco amigables responsables para la sostenibilidad con aplicación a los supermercados.

\section{RESULTADOS}

Interpretación de percepciones de prácticas eco-amigables con el medio ambiente, según gerentes de supermercados

Nos ofrecen su punto de vista los ejecutivos de los supermercados Plaza Vea (PV) y Negolatina (NL):

\section{Los productos, envases y eco etiquetas desde la cultura eco-amigable.}

"La línea de productos ecológicos son distribuidos en diferentes áreas del supermercado, estos productos tienen distinta sensibilidad de compra. Yo asumo los productos ecológicos como saludables, en vez de tener un cepillo normal tener un cepillo de bambú. Ejemplo invertir en cepillos de bambú cotizando nos va dar entre 6 a 8 de lo normal que está 2.5 soles esto nos afectaría. Estos productos ecológicos tienen un público muy reducido" (PV y NL).

En la concepción ejecutiva en productos eco amigables, esta responde desde la orientación centrada en el vendedor, ellos tienen una clara noción de productos saludables y los relacionan con la materia orgánica que forma el producto final y los que exceden los parámetros de alimentación saludable. En compras la demanda define tipos clientes, los sensibles en compras saludables que es un segmento aun reducido de compradores. En las inversiones es determinante los precios para ofertar productos sean normales de precio bajo y los llamados amigables de precios super-altos, estos afectan la optimización del capital de la empresa. La organización de productos o líneas de productos ecológicos aun no los diferencia de los negocios sostenibles y comprometidos con el medio ambiente. No hacen referencia sobre a envases eco amigables y eco 
etiquetas. Aún recién están enfocándose y construyendo su compromiso con la responsabilidad social y conciencia ambiental.

\section{Los residuos sólidos, su disposición y valorización desde la gestión de reciclaje}

"Hay un encargado que recoge por ejemplo los plásticos o cajas y otros, vienen a recogerlo de la empresa porque tienen un contrato con nosotros y ellos reciclan y reúsan los residuos. Nosotros hemos tratado de trabajar con una empresa recicladora, pero esta no podía sostenerse y ahora estas cajas están siendo utilizadas por las personas que deseen llevar sus productos en ella. Aparte con el apoyo de la municipalidad de Puno, con el programa reciclaje, se está logrando hacer parte del reciclaje, pero tampoco es muy efectiva" (PV y NL).

En estrategia de disposición de residuos sólidos, nace desde las empresas la intención de recojo de desechos cartones, papeles, tetra pack, bolsas, vidrios etc. para mantener las instalaciones limpias, saludables y amigables. La estrategia de valorización de sus desechos no es de interés de las empresas como una contribución sobre sus ingresos. Optan por la tercerización de sus residuos sólidos y son estas empresas que las reciclan y reúsan los residuos. Algunas empresas de reciclaje no cumplen eficientemente su tarea y no son sostenibles, tampoco está dando resultados sobre la disposición de sus residuos con el programa de reciclaje de la municipalidad el cual es poco efectiva. Lo positivo es la disposición de donar algunos materiales como cajas para que le den un uso mejor las personas.

\section{El consumo de energía eléctrica y agua basado en la reducción y ahorro}

"El uso de energía eléctrica se está reduciendo donde no se necesita, de igual manera en agua. También reducir el uso de implementos domésticos en la empresa”. Claro, nosotros hemos implementado el tema de energía bajo el uso de focos LED, aparte en equipos de refrigeración se pasó a equipos refrigerantes eco-amigables", esas políticas tenemos actualmente con respecto al tema del ahorro de energía y agua" (PV y NL).

La gestión de reducir energía eléctrica adquiere importancia en las empresas, son sensibles al uso de focos LED, logran ahorros, y rendimiento en iluminación y toman conciencia con la protección del medio ambiente. La implementación de equipos refrigerantes eco amigable los ha acercado más con su compromiso y con la cultura medioambiental. El agua no es muy considerada como actividad relevante a no dar detalles del mismo, y solo propenden su reducción de consumo. El ahorro de energía es una práctica que va en aumento en el país y lo difunde 
OSINERMING y las empresas eléctricas por el impacto que causa en el deterioro del medio ambiente.

\section{La comunicación e infraestructura como imagen de concientización eco amigable}

"Sobre medio ambiente se dan capacitaciones con diferentes expositores de áreas relacionadas y ellos efectúan la difusión de temas de compromiso ambiental, nuestro formato es amplio y buscamos una mejor atención. Nosotros tenemos dos reuniones importantes al año, una reunión por el día del trabajo y día de la empresa, donde sensibilizamos como ha ido evolucionando la empresa, cambios y algunos procesos que tienen que ver con presupuesto para poder desarrollar este aspecto ambiental e instalaciones. La última charla que se realizó, se enfatizó el tema del uso de bolsas de plástico y la diferencia con las bolsas biodegradables u oxi-biodegradables. Con las bolsas antiguas no se tenía el problema de regalar por su precio de 0.006 céntimos. En eso ustedes pueden ver que hay un cambio donde un $20 \%$ traen sus propias bolsas para realizar sus compras" (PV y NL).

La comunicación ambiental nace de charlas y capacitaciones al personal para lograr su compromiso con la empresa y una mejor atención a los clientes. Los temas ambientales lo orientan a comunicar a través de sus bolsas eco amigables su compromiso con el medio ambiente y sensibilizar hacia un cambio en sus clientes por el respeto ambiental. Las instalaciones tratan de presentarlas de mejor manera a sus clientes para ello destinan presupuestos.

Se ha elaborado la siguiente tabla donde se aprecia y percibe claramente un modelo teórico de gestión de prácticas eco amigables para supermercados:

Tabla 1. Modelo de gestión de prácticas eco amigables para supermercados

\begin{tabular}{lll}
\hline Actividad macro & $\begin{array}{l}\text { Procesos y relaciones } \\
\text { micro }\end{array}$ & Resultado \\
\hline & $\begin{array}{l}\text { Prácticas: Productos, } \\
\text { envases y eco etiquetas. }\end{array}$ & $\begin{array}{l}\text { Impacto económico: } \\
\text { Compras verdes. }\end{array}$ \\
\cline { 2 - 3 } $\begin{array}{ll}\text { Gestión de prácticas } \\
\text { eco amigables. }\end{array}$ & $\begin{array}{l}\text { Prácticas: Residuos, energía } \\
\text { y agua. }\end{array}$ & $\begin{array}{l}\text { Impacto social: } \\
\text { Compromiso responsable } \\
\text { en residuos. }\end{array}$ \\
\cline { 2 - 3 } & $\begin{array}{l}\text { Prácticas: Comunicación e } \\
\text { infraestructura amigable. }\end{array}$ & $\begin{array}{l}\text { Impacto medio ambiental: } \\
\text { Aprendizaje responsable } \\
\text { ambiental. }\end{array}$ \\
\hline
\end{tabular}

Fuente: Sistematización según antecedentes y entrevistas, 2019 
En la tabla 1, se aprecia una taxonomía de categorías: primero, la actividad macro centrada en la gestión eco amigable; el segundo tiene que ver con las relaciones y procesos micro de prácticas eco amigables, y tercero los resultados son el impacto de la gestión sostenible eco amigable. Este modelo teórico para la gestión eco amigable de los supermercados, sistematiza y permite la prospectiva de las prácticas eco amigables sostenibles de responsabilidad y compromiso con el medio ambiente.

\section{Descripción y evaluación del nivel de prácticas eco-amigables con el medio ambiente de los} supermercados, según estudiantes universitarios

Tabla 2. Nivel de presencia de productos alimenticios eco amigables.

\begin{tabular}{lcc}
\hline Categorías & Frecuencias & Porcentaje \\
\hline Muy alto & 0 & $0 \%$ \\
Alto & 22 & $24 \%$ \\
Regular & 54 & $58 \%$ \\
Bajo & 17 & $18 \%$ \\
Muy bajo & 0 & $0 \%$ \\
\hline Total & $\mathbf{9 3}$ & $\mathbf{1 0 0 \%}$
\end{tabular}

Fuente: Encuesta aplicada a estudiantes universitarios Puno, 2019

En productos alimenticios ecológicos u orgánicos, una calificación nivel regular 58\%, nivel alto $24 \%$ y nivel bajo $18 \%$. La comercialización de productos eco amigables es regular (54 estudiantes), presencia de líneas y marcas transnacionales, nacionales y de pequeñas empresas locales (estas promocionan productos orgánicos de la zona).

Tabla 3. Nivel de productos con eco etiqueta y octógono

\begin{tabular}{lcc}
\hline Categorías & Frecuencias & Porcentaje \\
\hline Muy alto & 21 & $23 \%$ \\
Alto & 33 & $35 \%$ \\
Regular & 27 & $29 \%$ \\
Bajo & 9 & $10 \%$ \\
Muy bajo & 3 & $3 \%$ \\
\hline Total & $\mathbf{9 3}$ & $\mathbf{1 0 0 \%}$ \\
\hline
\end{tabular}

Fuente: Encuesta aplicada a estudiantes universitarios Puno, 2019

En productos procesados con eco etiqueta que incluye el octógono, una calificación de alto $35 \%$, regular $29 \%$, muy alto $23 \%$ y bajo $10 \%$. La información del octógono es alta (33 estudiantes) principalmente en refrescos, lácteos, snack, chocolates, galletas etc.

Tabla 4. Nivel de productos con envase eco amigable.

\begin{tabular}{lll}
\hline Categorías & Frecuencias & Porcentaje \\
\hline
\end{tabular}




\begin{tabular}{lcc} 
Muy alto & 15 & $16 \%$ \\
Alto & 26 & $28 \%$ \\
Regular & 29 & $31 \%$ \\
Bajo & 14 & $15 \%$ \\
Muy bajo & 9 & $10 \%$ \\
\hline Total & $\mathbf{9 3}$ & $\mathbf{1 0 0 \%}$ \\
\hline
\end{tabular}

Fuente: Encuesta aplicada a estudiantes universitarios Puno, 2019

En productos con envase eco-amigable, una calificación de regular $31 \%$, alto $28 \%$, alto $16 \%$, bajo $15 \%$ y muy bajo $10 \%$. En envase eco-amigable regular (29 estudiantes), se encuentran envases biodegradables, eco cajas y materiales tradicionales cartón, vidrio y metal.

Tabla 5. Nivel de uso de bolsas de despacho eco amigables

\begin{tabular}{lcc}
\hline Categorías & Frecuencias & Porcentaje \\
\hline Muy alto & 22 & $24 \%$ \\
Alto & 37 & $40 \%$ \\
Regular & 21 & $23 \%$ \\
Bajo & 9 & $10 \%$ \\
Muy bajo & 4 & $4 \%$ \\
\hline Total & $\mathbf{9 3}$ & $\mathbf{1 0 0 \%}$ \\
\hline
\end{tabular}

Fuente: Encuesta aplicada a estudiantes universitarios Puno, 2019

El uso de bolsas de despacho eco-amigables, una calificación de alto 40\%, muy alto $24 \%$, regular $23 \%$ y muy alto $24 \%$. El uso de bolsas eco-amigables es alto (37 estudiantes) presencia de bolsas biodegradables y compostable, oxo-biodegradables. Para comprar bolsas de un solo uso u optan por llevar mochilas o bolsas personales.

Tabla 6. Nivel de manejo de residuos, energía y agua

\begin{tabular}{lcc}
\hline Categorías & Frecuencias & Porcentaje \\
\hline Muy buena & 18 & $19 \%$ \\
Buena & 21 & $23 \%$ \\
Regular & 28 & $30 \%$ \\
Mala & 20 & $22 \%$ \\
Muy mala & 6 & $6 \%$ \\
\hline Total & $\mathbf{9 3}$ & $\mathbf{1 0 0 \%}$ \\
\hline
\end{tabular}

Fuente: Encuesta aplicada a estudiantes universitarios Puno, 2019

En la gestión de residuos, energía y agua, una calificación de regular 30\%, buena $23 \%$, mala $22 \%$, muy buena $19 \%$ y muy mala $6 \%$. El manejo de residuos es regular (28 estudiantes) en desechos inorgánicos envases plásticos de polietileno y duros, cartón, papel, tetra pack y vidrio, pequeños módulos de recojo de residuos sólidos. En desechos orgánicos sobrantes de 
platos, verduras y cárnicos. En gestión de energía uso de luminarias ahorradoras y políticas de reducción de consumo de agua.

Tabla 7. Nivel de comunicación eco amigable.

\begin{tabular}{lcc}
\hline Categorías & Frecuencias & Porcentaje \\
\hline Muy buena & 4 & $4 \%$ \\
Buena & 19 & $20 \%$ \\
Regular & 41 & $44 \%$ \\
Mala & 18 & $19 \%$ \\
Muy mala & 11 & $12 \%$ \\
\hline Total & 93 & $100 \%$ \\
\hline \multicolumn{2}{c}{ Fuente: Encuesta aplicada a estudiantes universitarios Puno, 2019}
\end{tabular}

En comunicación eco amigable, una calificación de regular 44\%, buena 20\%, mala 19\% y muy mala $12 \%$. En comunicación medioambiental regular (41 estudiantes) en capacitación en responsabilidad social y medio ambiental, buenas prácticas de atención al cliente, página web etc.

Tabla 8. Nivel de infraestructura eco amigable.

\begin{tabular}{lcc}
\hline Categorías & Frecuencias & Porcentaje \\
\hline Muy buena & 22 & $24 \%$ \\
Buena & 33 & $35 \%$ \\
Regular & 31 & $33 \%$ \\
Mala & 7 & $8 \%$ \\
Muy mala & 0 & $0 \%$ \\
\hline Total & $\mathbf{9 3}$ & $\mathbf{1 0 0 \%}$ \\
\hline
\end{tabular}

Fuente: Encuesta aplicada a estudiantes universitarios Puno, 2019

En infraestructura una calificación de nivel buena 35\%, regular 33\% y muy bueno $24 \%$. En apariencia de infraestructura es buena (33 estudiantes). Ambiente limpio e higiénico, buena iluminación, color atractivo y buena distribución de secciones de productos.

Se ha elaborado una tabla consolidando la aplicación de la gestión de prácticas eco amigables de los supermercados:

Tabla 9. Resumen consolidado de gestión de prácticas eco amigables en supermercados.

$\begin{array}{lll}\text { Actividades macro (1) } & \text { Procesos y relaciones micro (9) } & \text { Resultados (37\%) }\end{array}$

$\begin{array}{ll}\text { Prácticas de eco productos } & \text { Impacto económico: } \\ \text { Prácticas de eco envases } & \text { Regular / Bueno: } 41 \% \\ \text { Prácticas de bolsas plásticas } & \\ \text { Prácticas de eco etiquetas } & \end{array}$




\begin{tabular}{lll}
\hline $\begin{array}{c}\text { Gestión de prácticas eco } \\
\text { amigable. }\end{array}$ & $\begin{array}{l}\text { Prácticas de residuos } \\
\text { Prácticas de energía } \\
\text { Prácticas de agua }\end{array}$ & $\begin{array}{c}\text { Impacto social: } \\
\text { Regular: } 30 \%\end{array}$ \\
& $\begin{array}{ll}\text { Prácticas de comunicación } \\
\text { Prácticas de infraestructura }\end{array}$ & $\begin{array}{l}\text { Impacto ambiental: } \\
\text { Regular / bueno: } 40 \%\end{array}$ \\
\hline
\end{tabular}

Fuente: Propia en base a resultados de evaluación prácticas eco amigables, 2019

En resumen, el nivel de gestión de prácticas eco amigables es regular en aplicación de prácticas eco amigables en los supermercados, estos tienen un impacto en el medio ambiente y de compromiso responsable de las empresas.

\section{DISCUSIÓN}

\section{De los resultados en prácticas, productos, envases y eco etiquetas}

Con respecto a la comercialización de productos eco amigables, resultó que es el sello distintivo de las empresas sostenibles, sensibles a adquirir sus productos de proveedores eco amigables y comprometidos con el medio ambiente. En los resultados de la percepción de los estudiantes universitarios es regular en $58 \%$ la presencia de productos eco amigables, los alimentos con marcas transnacionales son más difundidos y preferidos que los de proveedores locales. A pesar de la tendencia de consumo hacia alimentos orgánicos y saludables, el precio es determinante en los productos orgánicos, estos pertenecen aún a un segmento reducido de compradores sensibles a una alimentación saludable y pagan precios sobre el promedio, aquí es donde tienen ventajas los proveedores locales de productos orgánicos. Haciendo una comparación con las estrategias comerciales de productos orgánicos que implementan los supermercados de Lima, aún hay una distancia de oferta como lo señala Storino (2013) En tiendas de supermercados de Lima destacan las ventas de productos ecológicos, sin plomo, sin CFC (cloro fluoruro carbonato); los productos llevan eco etiquetas que identifican esa información y es sensible a determinados grupos de interés.

En relación a la presencia de envases y eco etiquetas amigables, los resultados indican un nivel de regular con el $31 \%$ y bueno con el $35 \%$ respectivamente; ello es producto del ajuste gradual con el compromiso del consumidor y la protección del medio ambiente de los supermercados. El cual se destaca en Rivera (2019) y PROMPERÚ (2016) los empaques y envases amigables con el medio ambiente, se convierten en la estrategia para contribuir a la sustentabilidad del medioambiente y también cumplen la función de hacerla atractiva al consumidor. Por otro 
lado, la norma Peruana establece el uso obligatorio del etiquetado frontal en todos los productos procesados y ultra procesados que son altos en azúcar, sodio, grasas saturadas y que contienen grasas transgénicas (Ley N³0021).

Los resultados de la investigación sobre el uso de bolsas de plástico biodegradables por los supermercados, obtiene un nivel bueno con $40 \%$. La presencia del uso para despacho de bolsas biodegradables y compostables en los supermercados es favorable y congruente con una cultura empresarial responsable y comprometida con la sostenibilidad y conciencia medio ambiental. Lo reafirma Pachamama (2019) en los establecimientos comerciales como Plaza Vea y otros de la ciudad de Puno, se dejaron de entregar bolsas de plástico de un solo uso de manera gratuita por ser contaminante y tienen un valor de 10 céntimos. Se suma cuando señala Green y DeMeo (2012) algunos productos de plástico, envases descartables son considerados no ser amigables y perjudiciales con el medio ambiente y ecosistema, y estos son los llamados productos de un solo uso. Además, en Perú la ley $\mathrm{N}^{\circ} 30884$ propende desincentivar el consumo de plásticos de un solo uso y envases o recipientes descartables vía impuestos a las bolsas plásticas.

\section{Los resultados en residuos, energía y agua}

En cuanto a residuos sólidos, los resultados de manejo de desechos inorgánicos muestran un nivel regular con un $30 \%$ en los supermercados. Se asemeja con los resultados a nivel nacional en promedio de $25 \%$, de supermercados Plaza Vea y Vivanda (7.3\% plástico, tetra pack $24.6 \%$, papel 29.2\% y vidrio 38,8\%) con lo que se está reduciendo el impacto ambiental. (Plaza Vea, 2019) y se considera que un 70\% corresponde a sustancias orgánicas (Díaz y Zea, 2017). Por otro lado, en residuos orgánicos, se sebe destacar a Tottus open plaza Piura en los que constituyen el 65.2\%, estos se degradan más rápido. (Seminario y Tineo, 2018). Según Eriksson (2015) para no desperdiciar los residuos orgánicos está la donación de alimentos, y en caso de ya no estar aptos para el consumo humano, se puede optar por la aplicación de los mismos para la generación de biogás.

Teniendo en cuenta a Jara (2014) los residuos sólidos o inorgánicos se producen al desembalar mercadería con cartones, papel y plásticos que deben ser recogidos por una empresa recicladora a fin de reutilizar lo posible. En referencia a residuos sólidos en los supermercados locales, no es una práctica el rescate de valoración de los residuos sólidos, más bien optan por la tercerización con empresas recicladoras. A nivel nacional señala Storino (2013) en supermercados peruanos (Los Olivos) se recicla el plástico 33\%, vidrio 67\%, Tetra pack y papel 100\%. Agrega Díaz y Zea (2017) en gestión de residuos, actualmente los Supermercados 
Peruanos vende la mayor parte de sus residuos a empresas como Kimberly Clark y Lindley para que ellos elaboren cajas, para el despacho de sus productos o desarrollen plásticos PET.

En referencia al manejo de energía y agua los supermercados locales han optado por el uso de focos LED para lograr el ahorro, y la implementación de equipos refrigerantes eco amigables, con ello son sensibles a políticas de reducir su consumo y protección del medio ambiente. Según Díaz y Zea (2017), en supermercados Peruanos respecto a la gestión de energía, se han implementado luminarias LED en todas las tiendas para disminuir el consumo interno y en la gestión de agua, ha implementado válvulas ahorradoras en tiendas, oficinas y centros de producción. Para Erikson (2015), una forma ahorrar energía y dinero es reducir la temperatura de almacenamiento para que los productos se conserven y tengan un tiempo más prolongado de vida. Señala Jara (2014), se guardan en cámaras de frío las frutas y verduras cuya temperatura oscila entre los $5^{\circ} \mathrm{C}$ y $7^{\circ} \mathrm{C}$; y carne, lácteos, fiambres y quesos la temperatura es entre $1^{\circ} \mathrm{C}$ y $4^{\circ} \mathrm{C}$.

\section{Los resultados en comunicación e infraestructura}

Con respecto a comunicación e imagen desde la percepción en estudiantes universitarios es regular con un $44 \%$, es limitada y se orienta más a capacitación en responsabilidad social, medio ambiente, buenas prácticas de atención al cliente. El enfoque de responsabilidad social de las empresas para Díaz y Zea (2017) conducen internamente a desarrollar actividades responsables en gestión de residuos, energía, agua y externamente les crea una buena imagen frente a los grupos de interés, si identifican que tienen políticas ambientales.

Finalmente, la gestión de prácticas ambientales de los supermercados locales, desde la percepción de estudiantes universitarios se califica como regular. Los resultados son similares a lo señalado por Storino (2013) "las prácticas ambientales que realizan los supermercados, Wong, Metro, Plaza Vea y Tottus aún son muy básicas, ya que estas son sencillas, no ameritan gran inversión, por lo que los programas de cuidado del medio ambiente no se ven reflejados en mayores beneficios para la empresa" (p. 45).

\section{CONCLUSIONES}

La gestión de prácticas eco amigables en los supermercados integralmente se califica como regular con un 37\% según la percepción de los estudiantes universitarios. 
La gestión de residuos, energía y agua (su disposición y valorización), esta requiere la atención como centros de generación de nuevos ingresos, así como mejorar estándares de reducción en el consumo de energía y agua en los supermercados.

La construcción de un modelo de gestión eco amigable parte con el dimensionamiento de sus bases empíricas en: Productos, envases y eco etiquetas. Residuos, energía y agua. Comunicación e infraestructura ambiental. Este debe responder a la sostenibilidad con compromiso social y ambiental de los supermercados

\section{REFERENCIAS BIBLIOGRÁFICAS}

Austermuhle, S. (2002). Sostenibilidad y ecoeficiencia en la empresa moderna. Perú: UPC.

Bohn, E, León, A. (2015). Diseño de packaging ecológico para producto en polvo soluble. Paliatea, 11(20). Pp.67-86.

Calomarde, J. (2000). Marketing ecológico. Editorial Pirámide, España

Chanduví, R. G. (2006) compostaje y vermicompostaje piramidal. Piura Perú. Recuperado en julio del 2017

Chullo, O. (2017) Tesis: Impacto de los supermercados en el mercado de abastos de Arequipa. Caso: Mercado San Camilo, 2017. Arequipa: Universidad Nacional de San Agustín.

Conama, (2010). Comunicación ambiental 2.0. Documento de trabajo de Congreso nacional sobre medio Ambiente, de fecha 28 de noviembre al 1 de diciembre 2016. Madrid.

Díaz, J. y Zea, S. (2017) Tesis: Responsabilidad social empresarial en el sector retail. Análisis de una empresa local a través del benchmarking de 3 empresas extranjeras en buenas prácticas de gestión medio ambiental durante el periodo 2012 - 2016. Caso: Supermercados Peruanos S.A. Lima. Universidad Peruana de Ciencias A.

Erikson, M. (2015). Prevention and management with focus on reduced waste for reduced carbonfootprint.Recuperadodehttp://pub.epsilon.slu.se/12756/1/Eriksson_m_151029.pdf

Esap (2005) Programa de cultura ambiental (documento de trabajo). Escuela superior de administración pública. Recuperado de www.esap.edu.pe.co-portal-index-php.

Gestión (19 de septiembre 2017). Perú en el "top ten" de países con más atractivo para invertir en retail. Recuperado de: http://www.colliers.com/media/files/latam/perú/gestion_top10peruretail.pdf. 
Green, K. \& DeMeo, E. (2012) The crusade against plastic bags. Pacific Research Institue. Recuperado de https://www.Pacificresearch.org/the-crusade- against-plastic-bags/

Jara, G. (2014) Proyecto de Supermercado "El Pueblo". Evaluación de impacto medioambiental, Paraguay.

Ley $\mathrm{N}^{\circ}$ 27314. Ley general de residuos sólidos. Perú. Recuperado en mayo del 2017 de http://www.vivienda.gob.pe/grd/normas/normasestadogrd/01\%20ley\%20grd\%20estado/ 01\%20ley\%20n\%c2\%bo\%2027314\%20\%20ley\%20general\%20de\%20residuos\%20soli dos.pdf

Ley $\mathrm{N}^{\circ}$ 30884. Ley que regula el plástico de un solo uso y los recipientes o envases descartables. Recuperado spijweb.minju.gob.pe/wpcontent/uploads/2018/12/19/ley-30884.pdf

Ley $N^{\circ}$ 30021. Ley de promoción de la alimentación saludable para niños, niñas y adolescentes. Perú. Diario el Peruano del 17 de mayo del 2013. Recuperado. www.leyes.congreso.gob.pe.documento-leyes-30021.

Minam (09 julio 2019) Minam incentiva uso de envases alternativos para empacar alimentos.https://www.gob.pe/institución/minam/noticias/45529-minam-incentiva- usode-envases-alternativos-para-empacar-alimentos.

Molina, N. I. (2011) Medidas operativas para la ecoeficiencia. Recuperado de http://datateca.unad,edu.co/contenidos/358049/AVA/Entorno_de_conocimiento/Conteni do_del_Curso/Modulo_Medidas_Operativas_para_la_Ecoeficiencia_Presentacion_pdf

Olivo, C.A. (2013). Medidas de eco eficiencia para el sector público. Actualidad Gubernamental.

Pachamama. (03 agosto 2019)) En Plaza Vea de Puno se vende la bolsa de plástica de un solo uso a 10 céntimos. (Ley 30884 del plástico). https://www.pachamama.org/regional/103puno/2266-enPlaza-vea-de-puno-se- vende-la-bolsa-de-plástica-de-un-solo-uso-a-10éntimos.

Patarroyo, C. (2019) Productos eco amigables para la comercialización de alimentos y bebidas. Informe. Bogotá: Universidad Santo Tomás.

Plaza Vea (2019). Sostenibilidad y responsabilidad social. Pasión por el planeta. Recuperado de https://www.plazavea.com.pe

Prom Perú. (2006) Informe especializado: Tendencias en envases para la industria alimentaria. Perú: Servicios al exportador, departamento de inteligencia de mercados.

Rivera, C., Conteras, F., Ariza, W., Bonilla, S., \& Cruz, A. (2019). Los empaques biodegradables, una respuesta a la consciencia ambiental de los consumidores. Realidad empresarial, (7), 2-8. https://doi.org/105377/reuca.vol7.7830. 
Secretaría de Ambiente y Desarrollo Sustentable (2005). Estrategia Nacional para la gestión Integral de Residuos Sólidos Urbanos. Buenos Aires. Argentina

Sedesol (2001) Manual para el establecimiento de un programa regional de reciclaje. Secretaria de desarrollo social México D.F.

Seminario, R. y Tineo, A. (2018) gestión de residuos sólidos en un hipermercado local. Tesis. Perú: Universidad de Piura

Storino, B. (2013) Falencias y oportunidades de gestión ambiental en los supermercados Wong, Metro, Plaza Vea y Tottus. Revista de Ciencias empresariales de la Universidad San Martín de Porres, Julio-diciembre. 4(2) Pp. 37-47.

\section{Conflicto de intereses / Competing interests:}

Los autores declaran que no incurren en conflictos de intereses.

\section{Rol de los autores / Authors Roles:}

Tomás Véliz: conceptualización, curación de datos, análisis formal, adquisición de fondos, investigación, metodología, administración del proyecto, recursos, software, supervisión, validación, visualización, escritura preparación del borrador original, escritura - revisar \& amp; edición.

Carol Véliz: conceptualización, análisis formal, investigación, metodología, administración del proyecto, recursos, software, supervisión, validación, visualización, escritura - preparación del borrador original, escritura - revisar \& amp; edición.

Mario Silva: conceptualización, investigación, metodología, administración del proyecto, recursos, software, supervisión, validación, visualización, escritura - preparación del borrador original, escritura - revisar \& amp; edición.

Rafael Escobedo: conceptualización, investigación, metodología, administración del proyecto, recursos, software, supervisión, validación, visualización, escritura - preparación del borrador original, escritura - revisar \& amp; edición.

Fuentes de financiamiento / Funding:

Los autores declaran que no recibieron un fondo específico para esta investigación.

\section{Aspectos éticos / legales; Ethics / legals:}

Los autores declaran no haber incurrido en aspectos antiéticos, ni haber omitido aspectos legales en la realización de la investigación. 